\title{
Potensi Lestari dan Status Pemanfaatan Ikan Kakap Merah dan Ikan Kerapu Di Selat Alas Propinsi Nusa Tenggara Barat
}

\author{
Didik Santoso \\ Program Studi Pendidikan Biologi, Jurusan PMIPA FKIP Universitas Mataram \\ Korespondensi Penulis : didiksantoso91@gmail.com
}

\begin{abstract}
ABSTRAK
Upaya untuk pengelolaan perikanan tangkap yang berpijak pada konsep efisiensi untuk meraih keunggulan komparatif dan kompetitif adalah dengan menentukan status pemanfaaatan ikan, khususnya ikan yang bernilai ekonomi penting sebagai tahap awal. Tujuan dari penelitian ini adalah menentukan potensi dan status pemanfaatan ikan kakap merah dan ikan kerapu di Selat Alas Propinsi NTB. Metode yang digunakan untuk menentukan tingkat pemanfaatan adalah dengan menggunakan potensi maksimum lestari dari Schaefer. Penelitian dilakukan di desa-desa nelayan di sekitar Selat Alas Propinsi Nusa Tenggara Barat (NTB). Potensi lestari (MSY) ikan kakap merah sebesar sebesar 205,8 ton/tahun, sedangkan ikan kerapu sebesar 259,1 ton/tahun. Status pemanfaatan ikan kerapu sebesar (Ephinephelus sp) 197,2\% tergolong status over exploited. Sedangkan ikan kakap merah (Lutjanus campechanus) sebesar 65,7\% berada dalam status moderately exploited.
\end{abstract}

Kata kunci : Moderately exploited, Over exploited, Persamaan Schaefer, Selat Alas, Propinsi NTB.

\begin{abstract}
For fisheries management which is based on the concept of efficiency to achieve comparative and competitive advantages is to determine utilization status of fish catch, particularly fish of economically important. The aim of this study is to determine utilization and potentian status of grouper and red snapper fish in the Alas Strait of West Nusa Tenggara Province. The method has been used to determine the level of utilization of fish by using the maximum sustainable yield of Schaefer.The study was conducted in the fishing villages around the Alas Strait West Nusa Tenggara Province. Sustainable yield (MSY) of grouper (Ephinephelus sp) is 259,1 ton/year, while red snapper (Lutjanus campechanus) is 205,8 ton/year. Utilization status grouper (Ephinephelus sp) is 197,2 in the state of over exploited. While the utilization of status of red snapper (Lutjanus campechanus) is $65,7 \%$ in the state of moderately exploited.
\end{abstract}

Key Word : Alas Strait, NTB Province, mayor fish catch, moderately exploited, over exploited, Schaefer Equation. 


\section{Pendahuluan}

Selat Alas merupakan wilayah perairan laut yang sangat penting bagi aktifitas penangkapan ikan nelayan klhususnya nelayan skala kecil di Propinsi Nusa Tenggara Barat (NTB). itu Pulau Lombok di bagian Barat dan Pulau Sumbawa di bagian Timur. Kegiatan penangkapan ikan merupakan aktivitas yang dilakukan untuk mendapatkan sejumlah hasil tangkapan. Sifat sumberdaya ikan meskipun dapat diperbaharui (renewable) namun perlu kehati hatian dalam pemanfaatannya untuk menjamin keberlanjutan, baik dalam jumlah maupun kemampuannya untuk regenerasi. Pauly et al. (2002) mengatakan bahwa kegiatan perikanan merupakan suatu kegiatan perburuan hewan air, tidak ada perburuan yang dilakukan secara industri di dunia ini, kecuali pada sumberdaya ikan. Pertimbangan aspek ekonomi akan menjadi lebih dominan dibandingkan dengan aspek lainnya. Satuan upaya perburuan tersebut akan melebihi kapasitas maksimumnya dan mengakibatkan kerusakan dan kepunahan sumberdaya yang bersangkutan.

Perikanan tangkap di Indonesia di dominasi oleh perikanan skala kecil (artisanal) dimana menjalani usaha dan kegiatan ekonominya untuk menghidupi keluarga sendiri, dengan skala yang begitu kecil sehingga hasilnya hanya cukup untuk memenuhi kebutuhan jangka waktu sangat pendek (Nikijuluw 2010). Nelayan skala kecil ini dicirikan oleh peralatan tangkap tradisional, modal usaha yang kecil dan organisasi penangkapan yang relatif sederhana (Sudarso 2008).

Ciri yang lain dari nelayan skala kecil adalah beragamnya jenis komoditas perikanan yang dihasilkan oleh nelayan skala kecil ini, sehingga menyebabkan rataan produksi tiap komoditas menjadi relatif kecil. Disamping itu terdapat berbagai macam teknologi penangkapan (multi gear multi species) sehingga menyebabkan kendala dalam pengusahaannya, terutama dalam permodalan dan pasar.

Salah satu wilayah perairan laut yang juga di dominasi oleh nelayan skala kecil ini adalah Selat Alas. Selat Alas ini juga berhubungan lansung dengan Laut Flores di bagian utara dan Samudera Hindia di bagian selatan (Gambar 1). Selat Alas merupakan wilayah perairan yang sangat penting bagi perekonomian masyarakat NTB, khususnya masyarakat yang bermukim di wilayah pesisir selat ini. Telah diketahui bersama bahwa Selat Alas merupakan salah satu wilayah perairan tempat penangkapan ikan kakap merah dan kerapu. Hal ini diperkuat oleh pendapat Blaber et al. (2005) yang menyatakan bahwa Selat Alas merupakan sentra penyebaran ikan kakap merah. Pernyataan ini sesuai dengan kondisi geografis dari Selat Alas dimana terdapat banyaknya terumbu karang disepanjang wilayah perairan ini. Terumbu karang merupakan habitat bagi berbagai jenis ikan yang bernilai ekonomi penting seperti kakap merah, baronang, kerapu, ikan napoleon dan lain-lain.

Tingginya permintaan terhadap berbagai jenis ikan menyebabkan terjadinya peningkatan terhadap upaya penangkapan, hal ini menyebabkan terjadinya gejala tangkap lebih (over fishing). Gejala tangkap lebih terhadap berbagai komoditas perikanan telah terjadi pula di perairan Selat Alas, salah satu penyebabnya adalah akibat adanya tekanan penangkapan yang disebabkan oleh 
tingginya jumlah nelayan yang menggantungkan hidupnya dari Selat Alas. Bachtiar (2005) menyatakan bahwa lebih dari $19 \%$ populasi penduduk kabupaten yang berhadapan langsung dengan Selat Alas (Kabupaten Lombok Timur dan Sumbawa Barat) hidup sebagai nelayan dan bertempat tinggal di Selat Alas.

Untuk mengatasi gejala tangkap lebih di perairan Selat Alas maka sangat penting dilakukan upaya pengelolaan mengingat sifat sumberdaya ikan meskipun dapat diperbaharui (renewable), namun perlu kehati hatian dalam pemanfaatannya untuk menjamin keberlanjutan baik dalam jumlah maupun kemampuannya untuk regenerasi. Sebagai tahap awal dalam kegiatan pengelolaan adalah mengetahui dinamika hasil tangkapan nelayan dan mengetahui tingkat pemanfaatannya, khususnya terhadap hasil tangkapan terhadap ikan-ikan yang bernilai ekonomis penting seperti kakap merah dan kerapu. Iklan-ikan yang bernilai ekonomis penting ini biasanya dicirikan oleh harga, produksi, dan permintaan pasar. Hendayana (2003) menyatakan bahwa komoditas ekonomis penting merupakan suatu jenis komoditas yang paling diminati dan memiliki nilai jual tinggi serta diharapkan mampu memberikan pemasukan yang besar dibandingkan dengan jenis yang lainnya. Komoditas yang benilai ekonomis penting dari sisi penawaran dicirikan oleh superioritas dalam harga sehingga dapat dijadikan andalan untuk meningkatkan pendapatan bagi nelayan.

Tujuan penelitian ini adalah menentukan potensi dan status pemanfaatan ikan kakap merah dan ikan kerapu di perairan Selat Alas Propinsi NTB.

\section{Bahan dan Metode}

Penelitian dilakukan pada bulan Juli - Desember 2012. Lokasi kajian dilakukan di desa nelayan di kawasan Selat Alas Propinsi NTB, Kabupaten Sumbawa Barat dan Kabupaten Lombok Timur (Tabel 1 dan Gambar 1). Desa-desa tersebut dijadikan lokasi kajian karena merupakan desa nelayan tradisioanal dimana pekerjaan menjadi nelayan ini merupakan pekerjaan utama bagi masyarakat setempat.

Tabel 1. Lokasi penelitian di sepanjang perairan Selat Alas Propinsi NTB

\begin{tabular}{|l|l|l|}
\hline \multicolumn{1}{|c|}{ Kabupaten } & \multicolumn{1}{|c|}{ Kecamatan } & Desa \\
\hline Sumbawa Barat & Sekongkang & Aik Kangkung \\
\cline { 2 - 3 } & Jereweh & Benete \\
\cline { 2 - 3 } & Taliwang & Labuhan Lalar \\
\cline { 2 - 3 } & Poto Tano & Poto Tano \\
\hline Lombok Timur & Keruak & Tanjung Luar \\
\cline { 2 - 3 } & Labuhan Haji & Labuhan Haji \\
\hline
\end{tabular}




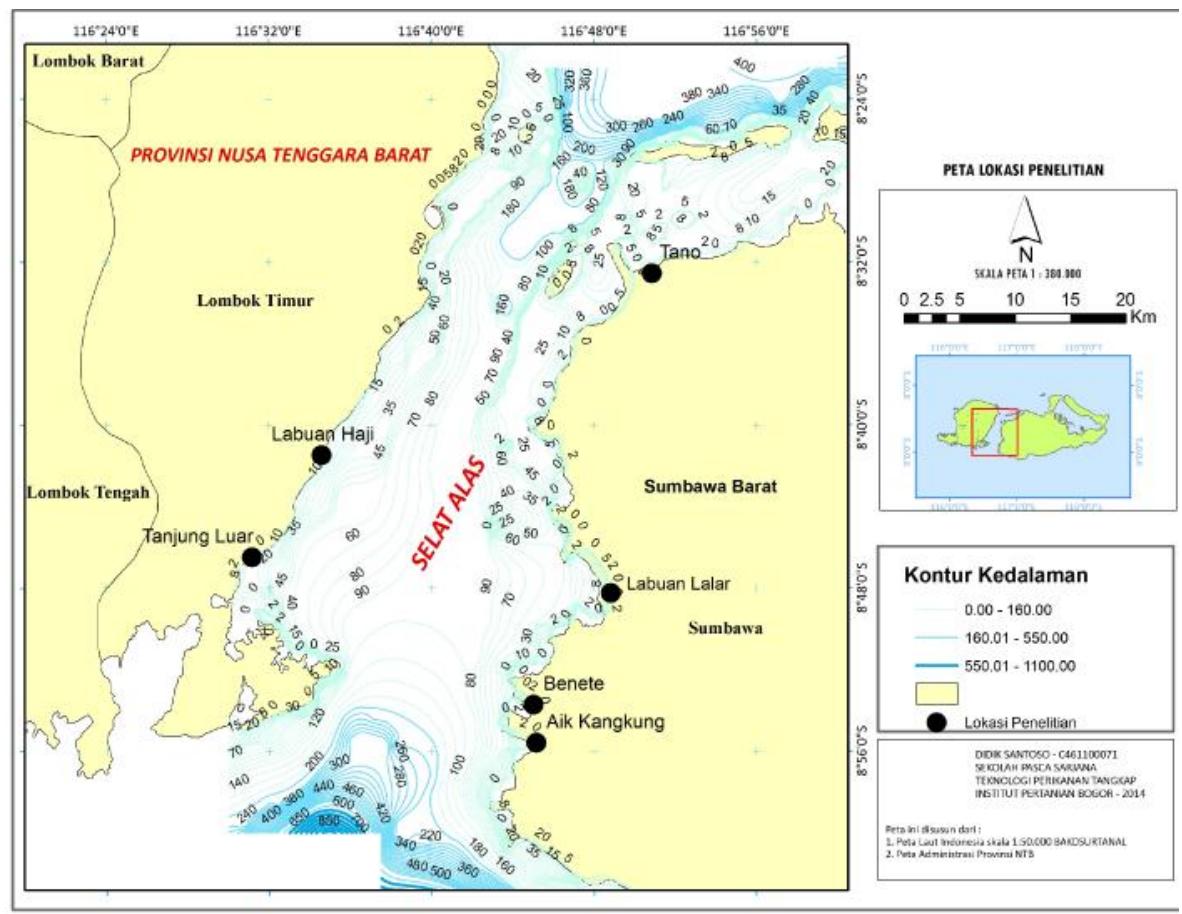

Gambar 1. Lokasi Penelitian di desa-desa nelayan di perairan Selat Alas, Propinsi NTB

Data dikumpulkan dengan menggunakan metode survei dan dokumentasi. Jenis data yang digunakan adalah data primer tangkap dapat dipakai sebagai alat tangkap dan data sekunder. Metode survai dilakukan untuk memperoleh data primer yang terdiri dari jenis ikan, produksi ikan dan jenis alat tangkap. Adapun metode dokumentasi dilakukan untuk memperoleh data sekunder yang terdiri dari data time series selama 10 tahun $(2003$ - 2012) dari statistik perikanan tangkap Propinsi NTB, Kabupaten Lombok Timur, dan Kabupaten Sumbawa Barat, yang meliputi data jenis ikan, produksi ikan hasil tangkapan, jumlah trip penangkapan, serta jumlah alat tangkap.

Analisis upaya penangkapan optimum dan produksi maksimum lestari ditentukan dengan langkah-langkah sebagai beirkut: (1) standardisasi alat tangkap, menurut Gulland (1983) bahwa jika di suatu perairan terdapat berbagai jenis alat (multi gear) maka salah satu alat standar. Alat tangkap lainnya dapat distandarisasikan terhadap alat tangkap yang telah dipilih sebagai alat tangkap standar tersebut. Alat tangkap yang dtetapkan sebagai alat tangkap standar dipilih dari alat tangkap yang mempunyai produktivitas yang paling tinggi. Upaya tangkap optimum (fopt) dan MSY dihitung dengan menggunakan persamaan Schaefer (Pauly 1983), yaitu :

$$
\begin{aligned}
& Y=(q k) f-\left(q^{2} K / r\right) f^{2} \\
& Y=a f-b f^{2}
\end{aligned}
$$

Keterangan :

$$
\mathrm{Y}=
$$

pertumbuhan alami

$$
\mathrm{K}=\text { daya }
$$

tampung (carrying capacyty)

$$
\mathrm{r} \quad=\quad \text { laju }
$$

pertumbuhan intrinsik 
sehingga dari rumus tersebut selanjutnya upaya optimum $\left(\mathrm{f}_{\mathrm{opt}}\right)$ dan potensi lestari maksimum (MSY) dihitung dengan menggunakan persamaan :

$$
\begin{aligned}
& \mathrm{f}_{\mathrm{opt}}=\frac{a}{2 b} \\
& \text { MSY }=\frac{a^{2}}{4 b}
\end{aligned}
$$

Keterangan :

$$
\begin{array}{ll}
\mathrm{a} & =\text { intersep } \\
\mathrm{b} & =\text { slope } \text { pada }
\end{array}
$$

persamaan regresi liner

(3) Menghitung tingkat pemanfaatan komoditas ikan unggulan, sebagai berikut :

Tingkat pemanfaatan $=\frac{C i}{M S Y} \times 100 \%$

Keterangan :

$$
\mathrm{Ci}=\text { Jumlah }
$$

hasil tangkapan saat ini

$$
\text { MSY = Maximum }
$$

Sustainable Yield

\section{Hasil Dan Pembahasan}

\section{Hasil}

Komposisi ikan hasil tangkapan nelayan Selat Alas selama penelitian terdiri dari ikan pelagis dan ikan demersal (ikan karang). Ikan-ikan pelagis seperti cumi-cumi, tongkol, dan cakalang mendominasi hasil tangkapan nelayan. Produksi tangkapan cumi-cumi menempati proporsi tertinggi yaitu sebesar $17 \%$ dari seluruh hasil tangkapan, kemudian diikuti oleh ikan yang lain seperti tongkol sebesar
9\%, dan cakalang sebesar $8 \%$. Ikan-ikan pelagis ini memang merupakan ikan yang biasanya berkelompok (schooling fish) sehingga ketika tertangkap biasanya dalam jumlah yang banyak.

Selat Alas juga merupakan daerah penangkapan ikan-ikan demersal (karang) yang bernilai ekonomi penting seperti kakap merah, dan kerapu. Hal ini terlihat dari hasil tangkapan nelayan responden yaitu untuk ikan kerapu sebesar $4 \%$ dan kakap merah sebesar 3,73\% dari seluruh hasil tangkapan. Ikan-ikan demersal tersebut masih dapat ditemukan oleh nelayan di perairan Selat Alas ini karena dasar perairan di wilayah pesisir dari selat ini di dominasi oleh terumbu karang yang menjadi habitat dari ikan-ikan demersal tersebut.

Nelayan di Selat Alas sebagain besar merupakan nelayan skala kecil, jenis dan ukuran alat tangkap yang dioperasikannya sangat beragam, namun demikian jenis alat yang dioperasikan di perairan ini adalah seperti payang atau dalam bahasa lokal disebut "jala oras", jaring insang hanyut, jaring klitik, jaring insang tetap, dan pancing (rawai hanyut, pancing tonda, dan pancing ulur) merupakan alat yang paling dominan dioperasikan. Perkembangan jumlah alat yang dioperasikan di Selat Alas ini seperti disajikan pada Gambar 2. 


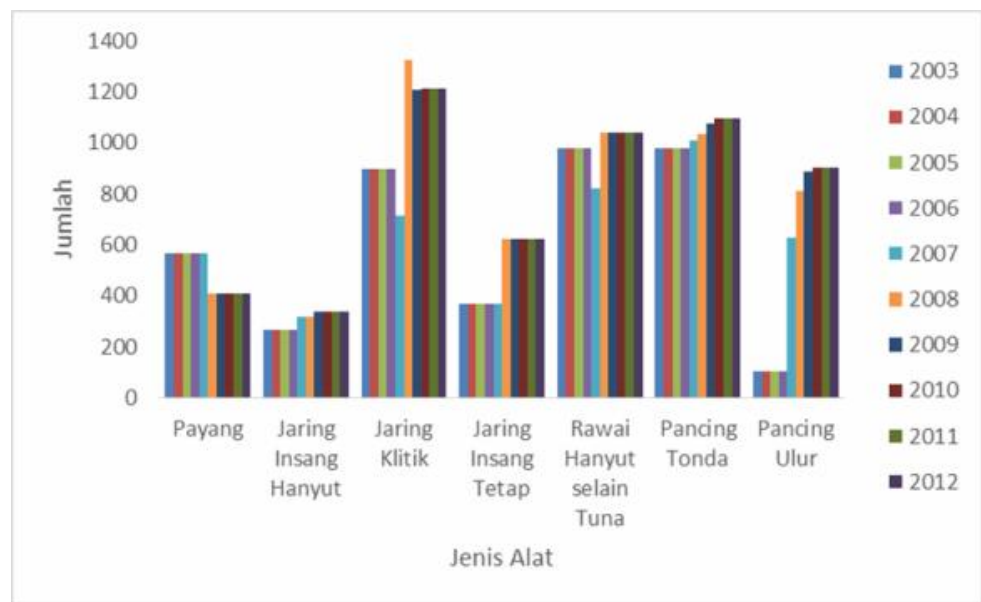

Gambar 2. Perkembangan jenis alat tangkap yang dioperasionalkan nelayan Selat Alas selama sepuluh tahun $(2003-2012)$.

Berdasarkan Gambar 2 terlihat bahwa jenis alat tangkap pancing ulur menunjukkan kecenderungan yang meningkat terutama pada lima tahun terakhir (2008 - 2012). Peningkatan ini menunjukkan bahwa penggunaan alat tangkap ini semakin banyak digunakan oleh nelayan. Alat tangkap pancing ulur ini biasa digunakan untuk menangkap ikan- ikan demersal (ikan karang) seperti ikan kakap dan kerapu.

Produksi cumi-cumi dan tongkol menunjukkan tren produksi yang terus meningkat (Gambar 3), terutama pada lima tahun terakhir (2008-2012). Sedangkan kerapu menunjukkan produksi yang meningkat pada tahun 2012. Sebaliknya cakalang dan kakap merah menunjukkan trend produksi yang menurun



Gambar 3. Trend produksi ikan tangkapan utama nelayan Selat Alas, 2003 - 2012

Hasil analisis potensi lestari maksimum (MSY) terhadap ikan kerapu dan kakap merah menunjukkan bahwa ikan kakap merah memiliki MSY terendah yaitu sebesar 205,8 ton/tahun, sedangkan ikan kerapu memiliki MSY sebesar 259,1 ton/tahun.(Tabel 2). 


$\begin{array}{lll}\text { Tingkat pengupayaan optimum } & \text { sebesar } 141.488 \text { trip/tahun, sedangkan ikan } \\ \left(\mathrm{f}_{\text {opt }}\right) \text { terhadap ikan kakap merah } & \text { kerapu sebesar } 74.564 \text { trip/tahun (Tabel } \\ \text { menduduki urutan tertinggi dengan } \mathrm{f}_{\text {opt }} & \text { 2). }\end{array}$

Tabel 2. Tingkat Pemanfaatan ikan tangkapan utama nelayan Selat Alas Propinsi NTB

\begin{tabular}{lccccc}
\hline Jenis ikan & $\begin{array}{c}\text { MSY } \\
(\text { Ton/tn) }\end{array}$ & $\begin{array}{c}\mathrm{f}_{\text {OPT }} \\
\text { (Trip/Tahun) }\end{array}$ & $\begin{array}{c}\mathrm{C}_{\text {terakhir }} \\
\text { (ton) }\end{array}$ & $\begin{array}{c}\text { TAC } \\
\text { (ton/tn) }\end{array}$ & $\begin{array}{c}\text { Tingkat } \\
\text { Pemanfaatan (\%) }\end{array}$ \\
\hline Kerapu & 259,1 & $74.563,5$ & 510,9 & 207,3 & 197,2 \\
Kakap merah & 205,8 & $141.488,4$ & 135,2 & 164,6 & 65,7 \\
\hline
\end{tabular}

Keterangan : MSY = Maximum Sustainable Yield (produksi maksimum lestari) $\mathrm{f}_{\mathrm{MSY}}=$ Efort MSY (upaya pada kondisi MSY); TAC = Total Allowable Catch (jumlah Tangkapan yang diperbolehkan sebesar $80 \%$ dari MSY).

Hasil analisis potensi maksimum lestari dengan menggunakan model Schaefer (Tabel 2) menunjukkan bahwa ikan kerapu tingkat pemanfaatannya telah melampaui potensi lestarinya atau dalam status over exploited. Sedangkan ikan kakap merah masih berada dibawah potensi lestarinya atau dalam status moderatly exploited.

\section{Pembahasan}

Selat Alas merupakan wilayah perairan yang potensial untuk penangkapan ikan kerapu dan kakap merah. Kondisi dimana beberapa bagian dasar perairan Selat Alas (terutama di bagian pesisir) tersusun dari ekosistem terumbu karang mendukung tingginya potensi ikan kerapu dan kakap merah di perairan ini. Kondisi ini didukung pendapat (Blaber et al. 2005) yang menggambarkan penyebaran ikan kakap merah di perairan Indonesia dan Australia dimana perairan NTB digambarkan sebagai salah satu lokasi konsentrasi ikan kakap merah.

Potensi tangkapan lestari ikan kerapu di Selat Alas diestimasi sebesar 259.1 ton/tahun, dan upaya optimum $\left(\mathrm{F}_{\mathrm{opt}}\right)$ sebesar 74,563.5 trip/tahun (Tabel 2), sedangkan rata-rata hasil tangkapan sebesar 510 ton/tahun dan rata-rata upaya oleh nelayan sebesar 76,568.9 trip/tahun, dengan demikian status ikan kerapu di Selat Alas adalah over exploited (Gambar 4). 
Gambar 4. Hubungan antara hasil tangkapan dengan upaya penangkapan ikan kerapu (Ephinephelus sp) di Selat Alas Propinsi NTB.

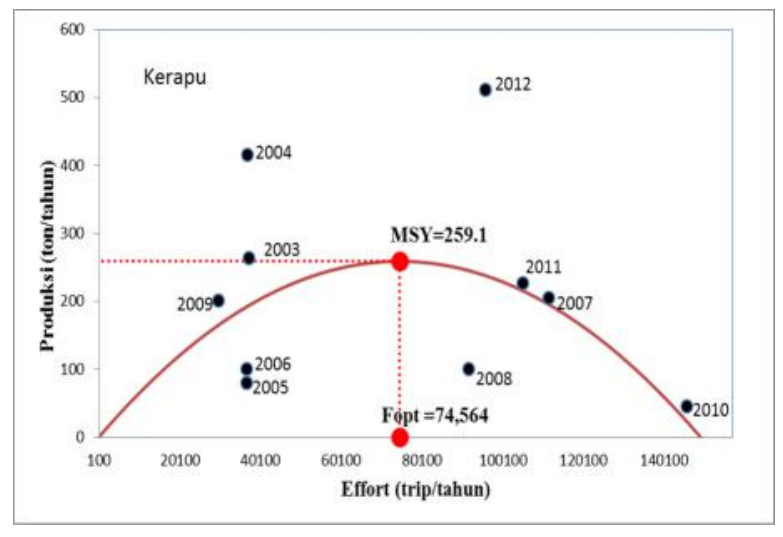

Dari Gambar 4 terlihat bahwa tingginya upaya penangkapan terhadap ikan kerapu menyebabkan terjadinya penangkapan berlebih terhadap ikan ini, terutama pada empat tahun terakhir (20092012). Tingginya upaya dan hasil tangkapan nelayan disebabkan oleh tingginya permintaan terhadap ikan kerapu ini terutama dalam kondisi hidup. Kondisi kerapu dalam kondisi hidup ini tidak hanya dipasarkan untuk keperluan konsumsi tetapi juga diusahakan oleh pembudidaya kerapu khususnya di wilayah Teluk Jukung di Desa Tanjung Luar dan Teluk Ekas di Desa Batu Nampar Kabupaten Lombok Timur Propinsi NTB untuk dibesarkan, pembesaran dilakukan di keramba jaring apung (KJA). Dengan status ikan kerapu dalam kondisi over Gambar 5. Hubungan antara hasil tangkapan dengan upaya penangkapan kakap merah (Lutjanus campechanus) di Selat Alas Propinsi NTB.




Hal ini didukung oleh pernyataan (Blaber et al. 2005) yang menyatakan bahwa salah satu konsentrasi sebaran ikan kakap merah di wilayah perairan Indonesia dan australia adalah di perairan NTB.

\section{Kesimpulan}

Dari uraian diatas dapat disimpulkan

bahwa :

1. Potensi lestari (MSY) ikan kerapu diestimasi sebesar 259,1 ton/tahun, sedangkan ikan kakap merah diestimasi sebesar 205,8 ton/tahun.

2. Status pemanfaatan ikan kerapu berada dalam status over exploited, sedangkan ikan kakap merah berada dalam status moderately exploited.

\section{Saran}

Untuk menjaga agar tidak terjadi tingkat pemanfaatan berlebih terhadap sumberdaya ikan di Selat Alas maka harus memperhatikan aspek kehati-hatian, misalnya dengan membatasi upaya penangkapan, memaksimalkan kearifan lokal yang selama ini berkembang dilingkungan masyarakat nelayan yang ada di Selat Alas, dan memperbanyak daerah konservasi perairan di perairan Selat Alas.

\section{Daftar Pustaka}

Bachtiar I. 2005. Integrating formal and customary approaches to responsible fisheries: a case study of District Fisheries Services in Nusa Tenggara Barat Province, Lombok, Indonesia. Fish for People 3 (2): 38-47.

Blaber, S.J.M., C.M. Dichmont, R.C. Bucworth, Badrudin, B. Sumiono, S.
Nurhakim, B. Iskandar, B. Fegan, D.C. Ramm, \& J.P. Salini. 2005. Share stock of snapper (Lutjanidae) in Australia and Indonesia: Integrating biology, population dynamics and socio-economics to examine management scenario. Rev.In Fish. Bop and Fish 15: 111127.

Gulland, J.A. 1983. Fish Stok Assesment : A Manual of Basic Methods. Chichester -New York-BrisbaneToronto- Singapore: John Willey and Sons. 223 p.

Hendayana, R. 2003. Aplikasi Metode Location Quotient (LQ) dalam Penentuan Komoditas Unggulan Nasional. Informatika Pertanian (1) : 658-675.

Nikijuluw, V.P.H. 2010. Populasi dan Sosial Ekonomi Masyarakat Pesisir serta Strategi Pemberdayaan Mereka Dalam Konteks Pengelolaan Sumberdaya Pesisir Secara Terpadu. Pusat Kajian Sumberdaya Pesisir dan Lautan, Institut Pertanian Bogor.

Pauly D. 1983. Some simple methods for the assessment of tropical fish stocks: Food \& Agriculture Org.

Pauly, D., V. Christensen, S. Guénette, T.J. Pitcher, U. R. Sumaila, C.J. Walters, R. Watson \& D. Zeller. 2002. Towards sustainability in world fisheries. Nature 418: 689695.

Santoso, D. M.S. Baskoro, D. Simbolon, Y. Novita, Mustaruddin. 2015. Pengelolaan Daerah Penangkapan Ikan Skala Tradisional Di Selat Alas Propinsi Nusa Tenggara Barat. Sekolah Pascasarjana, Institut Pertanian Bogor.

Sudarso. 2007. Tekanan Kemiskinan Struktural Komunitas Nelayan Tradisional Di Perkotaan. 
Masyarakat Kebudayaan Dan Politik. 2:13 - 28.

Suherman, B.J. 2013. Perkembangan Perikanan Cumi-Cumi Di Sentra Pendaratan Ikan Utara Pulau Jawa. Jurnal Penelitian Perikan Indonesia Vol.19 No. 1. Hal. 31-38.
Zainuddin, M. 2009. Estimasi Potensi Dan Pemetaan Daerah Potensial Penangkapan Ikan Pelagis Di Perairan Selayar Dengan Menggunakan Citra Satelit Aqua/Modis. Torani (Jurnal Ilmu Kelautan dan Perikanan ) Vol. 19 No.1. Hal $36-42$. 